\title{
PENGARUH KUALITAS PELAYANAN DAN PERSEPSI HARGA TERHADAP KEPUASAN DAN WOM PASIEN DI RSU PRIMA MEDIKA
}

\author{
Ni Kadek Tjintiadewi ${ }^{1}$ \\ I Ketut Rahyuda ${ }^{2}$
}

\author{
${ }^{1,2}$ Fakultas Ekonomi dan Bisnis Universitas Udayana, Bali, Indonesia \\ e-mail: tjintiadewi16@gmail.com
}

\begin{abstract}
ABSTRAK
Penelitian ini bertujuan untuk mengetahui pengaruh kualitas pelayanan dan persepsi harga terhadap kepuasan pelanggan dan word of mouth pada pasien rawat jalan di RSU Prima Medika. Penelitian ini dilakukan di Kota Denpasar dengan menggunakan ukuran sampel sebesar 100 orang dengan metode non-probability berbentuk purposive sampling. Pengumpulan data diperoleh dari hasil penyebaran kuesioner di RSU Prima Medika Denpasar dengan menggunakan sebanyak 19 indikator dan indikato-indikator tersebut diukur dengan menggunakan skala Likert. Adapun teknik analisis data yang digunakan dalam penelitian ini yaitu analisis jalur (path analysis) dan disertai dengan uji asumsi klasik. Hasil penelitian menemukan bahwa kualitas pelayanan dan persepsi harga secara parsial berpengaruh positif dan signifikan terhadap kepuasan pelanggan. Selain itu kualitas pelayanan, persepsi harga dan kepuasan pelanggan secara simultan berpengaruh positif dan signifikan terhadap word of mouth.
\end{abstract}

Kata kunci: kualitas pelayanan, persepsi harga, kepuasan pelanggan, word of mouth

\begin{abstract}
This study aims to determine the effect of service quality and price perceptions on customer satisfaction and word of mouth in outpatients at RSU Prima Medika. This research was conducted in Denpasar City by using sample size of 100 people with non-probability method in the form of purposive sampling. Data collection was obtained from questionnaires distributed at RSU Prima Medika Denpasar by using 19 indicators and the indicators were measured using Likert scale. The data analysis technique used in this research that is path analysis (path analyis) and accompanied by test of classical assumption. The results of the study found that service quality and price perception partially have a positive and significant effect on customer satisfaction. In addition, service quality, price perception and customer satisfaction simultaneously have a positive and significant influence on word of mouth.
\end{abstract}

Keywords: service quality, price perception, customer satisfaction, word of mouth 


\section{PENDAHULUAN}

Pada era globalisasi seperti saat ini, persaingan ketat terjadi baik pada perusahaan yang menghasilkan barang maupun jasa. Perusahaan akan dapat bertahan dan berkembang apabila menghasilkan barang ataupun jasa dengan kualitas yang baik. Kualitas sebagaimana yang diinterpretasikan ISO 9000 merupakan perpaduan antara sifat dan karakteristik yang menentukan sejauh mana keluaran dapat memenuhi persyaratan kebutuhan pelanggan. Salah satu aktivitas untuk menghasilkan kualitas yang baik adalah dengan cara pengendalian kualitas. American Society for Quality Control mendefinisikan kualitas sebagai totalitas fitur dan karakteristik produk atau jasa yang bergantung pada kemampuannya untuk memuaskan kebutuhan yang dinyatakan atau tersirat (Kotler dan Keller, 2009:143). Perusahaan yang ingin menghasilkan produk dengan standar yang sesuai dengan standar berwenang, perlu memperhatikan mengenai pengendalian kualitas

Dampak dari globalisasi juga berimbas pada salah satu perusahaan jasa yaitu rumah sakit. Rumah sakit merupakan institusi yang padat modal dan padat sumber daya manusia. Rumah sakit tidak lagi hanya mengemban misi sosial, namun aspek bisnis dalam pengelolaan suatu rumah sakit sudah menjadi hal yang wajar. Oleh karena itu, rumah sakit tidak perlu sungkan untuk lebih mempromosikan diri. Fasilitas dan sarana rumah sakit serta perkembangan ilmu kedokteran perlu disampaikan kepada masyarakat, melihat ketatnya persaingan dibidang pelayanan khususnya rumah sakit. 
Ni Kadek Tjintiadewi, Pengaruh Kualitas Pelayanan Dan Persepsi...

Di masa depan, kunci sukses suatu rumah sakit terletak pada dua hal pokok yaitu termanfaatkannya dengan efektif dan efisien sumber daya terutama SDM , dan kepuasan pengguna jasa rumah sakit (Trarintya, 2011). Namun dengan persaingan yang semakin ketat, kepuasan pemakai jasa rumah sakit tidak lagi menjadi hasil akhir yang diharapkan oleh rumah sakit. Kepuasan dari pemakai jasa rumah sakit akan semakin menguntungkan apabila mereka menceritakan pengalamannya selama berada di rumah sakit tersebut kepada pihak lain (Primantara, 2017).

Menurut Lovelock dan Wirtz (2011:74) kepuasan adalah suatu sikap yang diputuskan berdasarkan pengalaman yang didapatkan. Kepuasan pasien adalah cerminan kualitas pelayanan kesehatan yang diterima. Mutu pelayanan kesehatan berfokus pada tingkat kesempurnaan pelayanan kesehatan dalam menciptakan rasa puas pada pribadi setiap pasien. Semakin sempurna kepuasan tersebut, maka semakin baik juga mutu pelayanan kesehatan (Supartiningsih, 2017). Kepuasan pasien ialah salah satu usaha untuk menciptakan hubungan yang baik antara rumah sakit dengan pelanggan. Pasien yang memndapatkan produk atau jasa yang sesuai atau melebihi harapan, cenderung akan memberikan tanggapan yang positif bagi perusahaan salah satunya adalah memberikan word of mouth kepada orangorang di sekitarnya. Informasi dari mulut ke mulut yang positif menunjukkan bahwa perusahaan menghasilkan kepuasan pelanggan yang tinggi (Kotler, 2000).

Word of mouth (WOM) ialah perilaku mempengaruhi orang lain dalam bentuk penyampaian informasi mengenai produk baik barang maupun jasa kepada orang lain (Sulistiyowati, 2008). Metode yang efektif untuk membangun citra 
positif rumah sakit ialah dengan WOM. Selain itu, WOM merupakan cara jitu guna peningkatan jumlah kunjungan pasien serta penjualan jasa rumah sakit (Trarintya, 2011).

Perkembangan rumah sakit terjadi di seluruh Indonesia termasuk di Provinsi Bali. Dapat dilihat untuk data Rumah Sakit Pemerintah dan Swasta pada Tabel 1. kondisi Rumah Sakit Swasta di Provinsi Bali pada Tahun 2016 terdapat penambahan 1 buah rumah sakit baru di Kabupaten Gianyar yakni Rumah Sakit Kasih Ibu yang memiliki kapasitas tempat tidur sebanyak 38 buah. Namun, terjadi pengurangan 2 buah rumah sakit yakni Rumah Sakit Dharma Usadha dan Rumah Sakit Darmanata. Secara keseluruhan jumlah RS Swasta pada Tahun 2016 sebanyak 39 terdiri dari RS Umum sebanyak 32 buah dan RumahSakit Khusus sebanyak 7 buah dengan jumlah tempat tidur sebanyak 2.509 buah. Turunnya jumlah tempat tidur dibandingkan dengan Tahun 2015 dikarenakan adanya 1 rumah sakit sedang dalam renovasi dan 1 rumah sakit sudah berubah statusnya menjadi klinik.

Tabel 1.

Data Rumah Sakit Di Provinsi Bali Tahun 2016

\begin{tabular}{clcccr}
\hline \multirow{2}{*}{ No. } & Kab/Kota & RS Pemerintah & $\begin{array}{c}\text { TT (Tempat } \\
\text { Tidur) }\end{array}$ & RS Swasta & $\begin{array}{c}\text { TT (Tempat } \\
\text { Tidur) }\end{array}$ \\
\cline { 3 - 6 } & Buleleng & 2 & 359 & 4 & 327 \\
2 & Jembrana & 1 & 125 & 2 & 80 \\
3 & Tabanan & 1 & 246 & 5 & 195 \\
4 & Badung & 1 & 284 & 6 & 329 \\
5 & Denpasar & 5 & 1.149 & 13 & 1.024 \\
6 & Gianyar & 1 & 260 & 5 & 341 \\
7 & Klungkung & 1 & 143 & 2 & 92 \\
8 & Bangli & 2 & 457 & 1 & 57 \\
9 & Karangasem & 1 & 218 & 1 & 64 \\
Tahun & 2016 & 15 & 3.241 & 39 & 2.509 \\
Tahun & 2015 & 15 & 3.313 & 40 & 2.609 \\
\hline
\end{tabular}

Sumber: Buku Sarana Kesehatan Provinsi Bali, 2017 
Ni Kadek Tjintiadewi, Pengaruh Kualitas Pelayanan Dan Persepsi...

Dari data di atas, terlihat bahwa Kota Denpasar merupakan wilayah dengan jumlah rumah sakit paling banyak. Hal tersebut memperlihatkan tingkat persaingan yang tinggi terjadi dalam pemberian layanan kesehatan terutama pada RS Swasta. Dengan intensitas persaingan dan jumlah pesaing yang tinggi, manajemen rumah sakit dituntut agar dapat memenuhi kebutuhan pasien serta memberikan pelayanan yang optimal dan memuaskan dibandingkan pesaing jasa layanan kesehatan lainnya. Salah satu RS Swasta di Kota Denpasar yang mengutamakan kualitas pelayanannya adalah RSU Prima Medika.Hal ini diwujudkan dengan diraihnya Capaian Indikator Peningkatan Mutu dan Keselamatan Pasien Tahun 2016 (www.primamedika.com).

RSU Prima Medika berdiri di bawah naungan PT. Surya Prima Cipta ini memiliki visi yaitu 'Menjadi rumah sakit terbaik yang berdaya saing global' dan misi yaitu 'Menjaga mutu pelayanan, minimalisasi rantai birokrasi, ramah, profesional, menjalin hubungan yang erat dan harmonis serta berkesinambungan dengan customer, menciptakan suasana yang aman dan nyaman bagi customer dan karyawan, membentuk SDM yang berkualitas, kreatif, inovatif, efektif dan efisien. RSU Prima Medika merupakan salah satu rumah sakit yang menyusung konsep "Hotel' dimana kualitas dan kenyamanan pasien yang menjalani rawat inap sangat diutamakan. Hal ini sejalan dengan visi dan misi yang dijalankan oleh rumah sakit ini (www.primamedika.com).

Peter dan Olson (2000:228) dalam bukunya Consumer Behavior telah menyatakan bahwa, persepsi harga berkaitan dengan bagaimana informasi harga dipahami seluruhnya oleh konsumen dan memberikan makna yang dalam bagi 
mereka. Pada Tabel 2. ditampilkan rincian tarif kamar dan fasilitas yang tersedia pada setiap tipe-tipe kamar rawat inap.Harga-harga yang ditawarkan oleh RSU Prima Medika sudah sangat dipertimbangkan dan dianggap wajar karena sesuai dengan fasilitas dan pelayanan yang didapatkan.

\section{Tabel 2.}

Tarif Kamar dan Fasilitas di RSU Prima Medika Tahun 2016

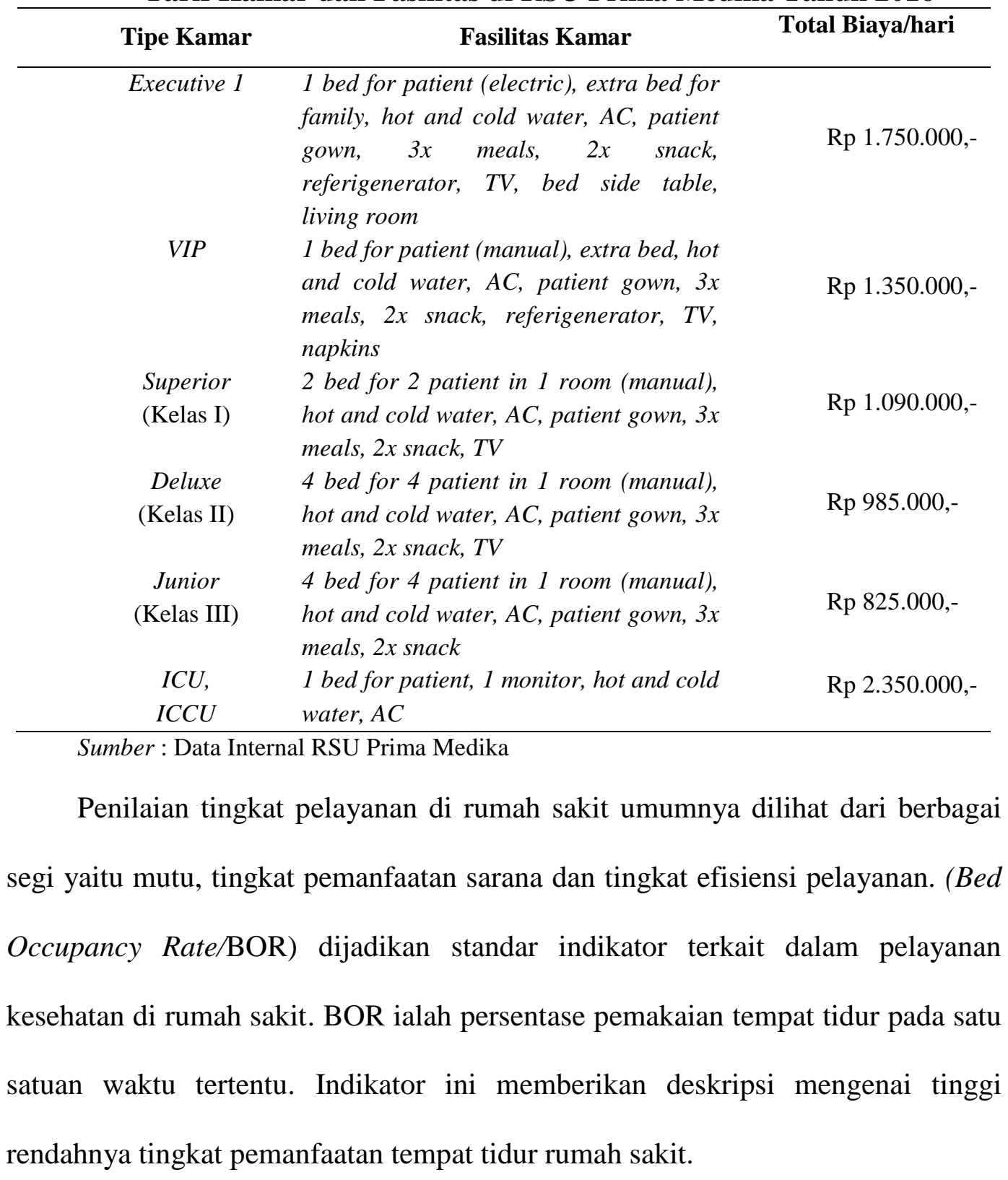


Ni Kadek Tjintiadewi, Pengaruh Kualitas Pelayanan Dan Persepsi...

Peneliti tidak menggunakan responden yang sedang menjalani rawat inap akan tetapi menggunakan responden yang menjalani rawat jalan baik yang sebelumnya pernah dirawat inap maupun yang hanya melakukan kontrol kesehatan rutin. Hal ini dikarenakan data rumah sakit sifatnya sangat privasi dan rahasia yang menjadikan sangat sulit untuk mendapatkan informasi.

Dalam penelitian ini, keempat variabel memiliki keterkaitan antara satu dengan yang lainnya. Sebuah rumah sakit yang memberikan kualitas pelayanan kesehatan yang baik dan melebihi dengan apa yang diharapkan pasiennya sudah tentu akan membuat pasien merasa puas. Dari rasa puas tersebut akan meningkatkan intensitas word of mouth positif yang dilakukan pasien ataupun pelanggan rumah sakit kepada orang-orang di sekitar. Hal ini akan berdampak pada meningkatnya citra positif rumah sakit di masyarakat. Selain itu, kewajaran harga yang dipersepsikan pelanggan sebanding dengan kualitas pelayanan yang diterima akan menimbulkan kepuasan karena besar uang yang dikeluarkan sebanding dengan pelayanan kesehatan yang diterima akan menimbulkan kepuasan dibenak pelanggan dan selanjutnya akan mendorong orang-orang disekitarnya untuk menggunakan jasa rumah sakit yang pernah dirasakan sebelumnya.

Beberapa penelitian telah dilakukan berkaitan dengan keempat variabel yang telah dipaparkan. Lily dan Yurike (2015) menyatakan bahwa kualitas layanan dan persepsi harga berpengaruh signifikan terhadap kepuasan. Hasil penelitian sebelumnya menunjukkan adanya research gap antara hubunganhubungan variabel. Molinari et al., (2008) dan Shao (2013) menemukan bahwa 
tidak ada hubungan yang signifikan antara kepuasan dengan perilaku word of mouth, sedangkan Saraswulandari dan Santika (2013) menemukan bahwa kepuasan konsumen berpengaruh positif dan signifikan terhadap word of mouth. Penelitian dari Shao (2013) juga menemukan bahwa kualitas layanan tidak memiliki pengaruh secara langsung terhadap word of mouth. Hasil penelitian ini berbeda dengan penelitian dari Harrison-Walker (2001) yang menemukan bahwa kualitas layanan berpengaruh positif dan signifikan terhadap word of mouth.

Penelitian yang dilakukan Utama (2003) menyimpulkan bahwa lima dimensi kualitas pelayanan, yaitu tangible, reliability, responsiveness, assurance, dan empathy berpengaruh terhadap kepuasan konsumen. Kualitas layanan merupakan salah satu variabel kuat yang mempengaruhi kepuasan konsumen, diikuti oleh variabel harga dan produk. Salah satu strategi perusahaan untuk meningkatkan dan mempertahankan pelanggannya adalah dengan mengoptimalkan kualitas pelayanan mereka. Firdous dan Rahela (2017) memberikan bukti empiris melalui penelitiannya untuk menunjukkan bahwa dimensi kualitas layanan internet banking merupakan faktor penting untuk memuaskan pelanggan karena masing-masing berkaitan positif dengan kepuasan pelanggan. Chen et al. (2016) menyatakan bahwa kualitas pelayanan berpengaruh positif terhadap kepuasan pelanggan secara keseluruhan. Hasil penelitian Setyawati (2009) menunjukkan bahwa kualitas pelayanan berpengaruh positif dan signifikan terhadap kepuasan pasien. Pada sektor perbankan, penggunaan teknologi yang didasari kualitas layanan memiliki pengaruh positif terhadap kepuasan (Ganguli dan Sanjit, 2011). Hasil penelitian Satmoko (2016) 
Ni Kadek Tjintiadewi, Pengaruh Kualitas Pelayanan Dan Persepsi...

menemukan bahwa kualitas pelayanan mempunyai tingkat korelasi yang kuat terhadap kepuasan konsumen dan berpengaruh positif terhadap kepuasan konsumen. Konsumen akan semakin merasa puas ketika mendapatkan kualitas pelayanan yang terbaik dan pada akhirnya akan meningkatkan keuntungan perusahaan. Berdasarkan hasil-hasil penelitian sebelumnya, rumusan hipotesis yang dapat diajukan, yaitu :

$\mathrm{H}_{1}$ : Kualitas pelayanan berpengaruh positif dan signifikan terhadap kepuasan pelanggan

Harga yang dilihat dari sudut pandang pelanggan, seringkali digunakan sebagai indikator nilai bila mana harga tersebut dihubungkan dengan manfaat yang dirasakan atas suatu barang atau jasa. Kertajaya (2002) mengungkapkan bahwa, indikator penilaian harga dapat dilihat dari kesesuaian antara suatu pengorbanan dari pelanggan terhadap nilai yang diterimanya setelah melakukan pembelian, dan dari situlah pelanggan akan mempersepsi dari produk atau jasa tersebut. Persepsi yang positif merupakan hasil dari rasa puas akan suatu pembelian yang dilakukan, sedangkan persepsi yang negatif merupakan suatu bentuk dari ketidakpuasan pelanggan atas produk atau jasa yang dibelinya. Penelitian yang dilakukan Devi dan Harry (2016) menemukan bahwa persepsi harga berpengaruh positif dan signifikan terhadap kepuasan pelanggan. Hasil penelitian Lily dan Yurike (2015) menunjukkan bahwa persepsiharga berpengaruh positif dan signifikan terhadap kepuasan pelanggan. Berdasarkan hasil-hasil penelitian sebelumnya, rumusan hipotesis yang dapat diajukan, yaitu :

$\mathrm{H}_{2}$ : Persepsi harga berpengaruh positif dan signifikan terhadap kepuasan pelanggan 
Berdasarkan hasil penelitian yang dilakukan Indriani dan Nurcaya (2015), kualitas pelayanan berpengaruh positif dan signifikan terhadap word of mouth (WOM), artinya semakin baik kualitas pelayanan yang diberikan akan mempengaruhi word of mouth (WOM) melalui pengguna jasa PT. Autobagus Rent A Car. Hasil penelitian Rifky dan Yessy (2015) membuktikan bahwa kualitas layanan berpengaruh positif signifikan terhadap WOM pasien BPJS di RSI Jemursari Surabaya. Hasil penelitian ini didukung oleh pendapat Reingen dan Walker (2001), yang mengemukakan bahwa media promosi melalui WOM 7 kali lebih efektif dibandingkan iklan di majalah dan koran, 4 kali lebih efektif dari personal selling serta 2 kali lebih efektif dari pada iklan radio pada usaha yang dilakukan oleh perusahaan dalam mempengaruhi pelanggan untuk beralih menggunakan produk perusahaan tersebut. Dipertegas lagi dengan hasil penelitian Liu dan Lee (2016) yang menemukan bahwa kualitas pelayan berpengaruh positif terhadap word of mouth. Berdasarkan hasil penelitian sebelumnya, rumusan hipotesis yang dapat diajukan, yaitu :

$\mathrm{H}_{3}$ : Kualitas pelayanan berpengaruh positif dan signifikan terhadap perilaku word of mouth

Hasil pengujian Nurjanah dan Mashariono (2017) menunjukkan bahwa harga tidak berpengaruh langsung terhadap word of mouth. Hasil ini menunjukkan semakin sesuai dan terjangkau harga pada depot bakso CJDW Pak Sam tidak akan meningkatkan word of mouth. Ketika terdapat perubahan harga pada depot bakso CJDW Pak Sam tidak akanmerubah kuantitas konsumen dalam melaksanakan word of mouth. Sedangkan, hasil penelitian Anik (2013) menunjukkan bahwa terdapat pengaruh antara harga terhadap word of mouth di Timezone Plaza 
Ni Kadek Tjintiadewi, Pengaruh Kualitas Pelayanan Dan Persepsi...

Surabaya, dimana pelanggan merekomendasikan perusahaan kepada orang lain atas tingkat harga yang diberikan oleh Timezone Plaza Surabaya karena sesuai dengan tawaran pengalaman yang diberikan. Ditambah lagi dengan penelitian Neni (2017) yang menyatakan bahwa variabel harga berpengaruh positif terhadap word of mouth secara signifikan.Berdasarkan hasil penelitian sebelumnya, rumusan hipotesis yang dapat diajukan, yaitu :

$\mathrm{H}_{4}$ : Persepsi harga berpengaruh positif dan signifikan terhadap perilaku word of mouth

Banyak penelitian menyebutkan bahwa, terdapat hubungan antara pengalaman baik positif ataupun negatif dari pemakaian suatu produk barang atau jasa dengan kepuasan konsumen, yang akhirnya dapat mendorong WOM baik positif atau negatif (Priharmoko, 2003). Erida (2009) menemukan bahwa kepuasan konsumen berpengaruh terhadap word of mouth. Penelitian yang dilakukan oleh Yuli dan Bagus (2014) menyatakan bahwa kepuasan pelanggan berpengaruh positif dan signifikan terhadap word of mouth. Primantara (2017) menemukan bahwa kepuasan memiliki dampak yang signifikan terhadap word of mouth, artinya apabila kepuasan konsumen mengalami perubahan maka word of mouth juga akan mengalami perubahan. Pengaruh hubungan ini menunjukkan nilai positif yang artinya, apabila tingkat kepuasan semakin tinggi maka akan tercipta word of mouth yang positif. Berdasarkan hasil penelitian sebelumnya, rumusan hipotesis yang dapat diajukan, yaitu :

$\mathrm{H}_{5}$ : Kepuasan pelanggan berpengaruh positif dan signifikan terhadap word of mouth 


\section{METODE PENELITIAN}

Penelitian ini menggunakan pendekatan kuantitatif dengan jenis penelitian asosiatif. Penelitian asosiatif mampu menjelaskan hubungan antara variabel satu dengan variabel lainnya. Indikator-indikator pembentuk variabel mengacu pada beberapa sumber yang telah dimodifikasi agar sesuai dengan subjek penelitian ini. Penelitian ini dilakukan untuk menjelaskan pengaruh kualitas pelayanan dan persepsi harga terhadap perilaku word of mouth melalui kepuasan pasien. Penelitian dilakukan pada RSU Prima Medika Denpasar dengan pengumpulan data melalui kuesioner. Teknik analisis yang digunakan adalah analisis jalur.

Penelitian ini dilakukan di RSU Prima Medika Denpasar yang berlokasi di Jalan Pulau Serangan No. 9X, Denpasar. Lokasi ini dipilih dengan pertimbangan RSU Prima Medika Denpasar berlokasi dipusat kota yang sangat strategis dan merupakan kawasan padat penduduk dengan mobilitas yang tinggi. RSU Prima Medika merupakan salah satu rumah sakit swasta dengan fasilitas canggih dan modern dengan pelayanan yang prima. Selain itu, letak RSU Prima Medika Denpasar berdampingan langsung dengan pesaing utamanya yaitu RSU Surya Husadha dan RS Wing Amertha Sanglah sehingga memerlukan strategi pemasaran untuk memenangkan persaingan baik dari segi harga, kelengkapan fasilitas dan pelayanan.

Objek dalam penelitian ini adalah perilaku pasien pasca mengkonsumsi kualitas jasa yang diberikan oleh RSU Prima Medika Denpasar, diantaranya adalah kualitas pelayanan, persepsi harga, kepuasan pelanggan, dan word of mouth. 
Ni Kadek Tjintiadewi, Pengaruh Kualitas Pelayanan Dan Persepsi...

Variabel bebas (independen) adalah variabel yang menjadi penyebab timbulnya atau berubahnya variabel terikat. Variabel bebas dalam penelitian ini disimbolkan dengan huruf $X$, yaitu variabel kualitas pelayanan $\left(X_{1}\right)$ dan persepsi harga $\left(\mathrm{X}_{2}\right)$. Kualitas pelayanan merupakan tingkat keunggulan yang diharapkan dan pengendalian atas tingkat keunggulan untuk memenuhi keinginan konsumen. Persepsi harga adalah cara konsumen melihat harga suatu produk yang ditawarkan oleh RSU Prima Medika untuk setiap pelayanannya

Variabel terikat (dependen) adalah variabel yang dipengaruhi atau yang menjadi akibat karena adanya variabel bebas. Variabel terikat dalam penelitian ini disimbolkan dengan huruf $\mathrm{Y}$, yaitu kepuasan pelanggan $\left(\mathrm{Y}_{1}\right)$ dan word of mouth $\left(\mathrm{Y}_{2}\right)$. Dalam penelitian ini, variabel kepuasan pelanggan akan lebih sering diganti dengan penggunaan kata kepuasan pasien. Hal ini dikarenakan pelanggan yang menggunakan jasa kesehatan di rumah sakit lebih lumrah disebut dengan pasien. Kepuasan pasien merupakan perasaan senang atau kecewa yang dirasakan oleh pasien RSU Prima Medika Denpasar sebagai hasil perbandingan dari kinerja produk yang dipersepsikan dengan apa yang diharapkan pasien. Word of mouth merupakan pernyataan secara personal atau non personal yang disampaikan oleh pengguna jasa kesehatan RSU Prima Medika Denpasar kepada konsumen lainnya.

Populasi dalam penelitian ini adalah konsumen yang sudah pernah menggunakan layanan jasa yang ditawarkan RSU Prima Medika Denpasar baik rawat inap maupun rawat jalan dalam kurun waktu 3-6 bulan terakhir. Penentuan jumlah sampel yang representatif menurut Ferdinand (2002) adalah jumlah indikator dikalikan 5 sampai dengan 10. Jumlah indikator yang digunakan dalam 
penelitian ini adalah 19 maka ukuran sampelnya berada pada rentang 95 - 190 . Berdasarkan pertimbangan maka ukuran sampel dalam penelitian ini ditetapkan sebanyak 100 responden. Penelitian ini menggunakan metode penentuan sampel nonprobability sampling yaitu teknik pengambilan sampel yang tidak memberi peluang/kesempatan sama bagi setiap unsur atau anggota populasi untuk dipilih menjadi sampel. Teknik pengambilan sampel yang dipilih dalam penelitian ini adalah purposive sampling. Purposive sampling merupakan metode pemilihan sampel berdasarkan pertimbangan tertentu (Sugiyono, 2017:85).

Jumlah sampel sebanyak 100 responden, dengan instrumen penelitian berupa kuesioner. Peneliti melakukan penyebaran kuesioner secara langsung di lokasi penelitian yaitu RSU Prima Medika dan juga melalui media elektronik yaitu Google form. Untuk persentase, penyebaran kuesioner secara langsung sebanyak $60 \%$ sedangkan melalui Google form sebanyak $40 \%$.

Data kuantitatif dalam penelitian ini berupa jumlah rumah sakit pemerintah dan rumah sakit swasta di provinsi Bali pada Tahun 2016 yang dihimpun dari Buku Sarana Kesehatan Provinsi Bali 2016. Selain itu, data kuantitatif juga ditujukkan pada data jumlah BOR periode 2002-2015 dan tarif kamar yang dihimpun dari data internal RSU Prima Medika serta jumlah responden yang digunakan dalam penelitian ini. Data kualitatif dalam penelitian ini adalah jawaban atas kuesioner yang diberikan kepada responden.

Sumber primer adalah responden yang memberikan data dengan cara menjawab kuesioner. Sumber sekunder merupakan data yang sudah lebih dahulu dikumpulkan dan dilaporkan oleh orang lain diluar peneliti. Sumber sekunder 
Ni Kadek Tjintiadewi, Pengaruh Kualitas Pelayanan Dan Persepsi...

yang digunakan adalah informasi dari internal rumah sakit, informasi dari website, buku-buku, dan jurnal yang berkaitan dengan pembahasan masalah.

Analisis jalur merupakan teknik model analisis yang digunakan untuk menganalisis pola hubungan antar variabel dengan tujuan untuk mengetahi pengaruh langsung maupun tidak langsung seperangkat variabel bebas terhadap variabel terikat (Riduwan dan Kuncoro, 2008:2).

Persamaan struktural

$$
\begin{aligned}
& \mathrm{Y}_{1}=\beta_{1} \mathrm{X}_{1}+\beta_{2} \mathrm{X}_{2}+\mathrm{e}_{1} \ldots \ldots \ldots \\
& \mathrm{Y}_{2}=\beta_{3} \mathrm{X}_{1}+\beta_{4} \mathrm{X}_{2}+\beta_{5} \mathrm{Y}_{1}+\mathrm{e}_{2}
\end{aligned}
$$

Keterangan :

$$
\begin{array}{ll}
\mathrm{Y}_{1} & =\text { Kepuasan pelanggan } \\
\mathrm{Y}_{2} & =\text { Word Of Mouth } \\
\mathrm{X}_{1} & =\text { Kualitas pelayanan } \\
\mathrm{X}_{2} & =\text { Persepsi harga } \\
\beta & =\text { Koefisien garis regresi } \\
\mathrm{e}_{1} & =\text { error } 1 \\
\mathrm{e}_{2} & =\text { error } 2
\end{array}
$$

Untuk mengetahui nilai dari koefisien regresi $\left({ }^{\beta}\right)$ digunakan SPSS 13. Setelah menghitung koefisien regresi, selanjutnya dapat dihitung nilai error 1 dan error 2 dengan menggunakan rumus sebagai berikut,

$$
\mathrm{e}=\sqrt{1-R^{2}}
$$

Keterangan :

$$
\begin{array}{ll}
\mathrm{e} & =\text { Error } \\
\mathrm{R}^{2} & =\text { Koefisien determinasi }
\end{array}
$$

Setelah nilai dari error 1 dan error 2 diketahui, maka selanjutnya dapat dihitung nilai dari koefisien determinasi total dengan rumus sebagai berikut :

$$
\mathrm{R}^{2} \mathrm{~m}=1-\left(\mathrm{Pe}_{1}\right)^{2}\left(\mathrm{Pe}_{2}\right)^{2}
$$




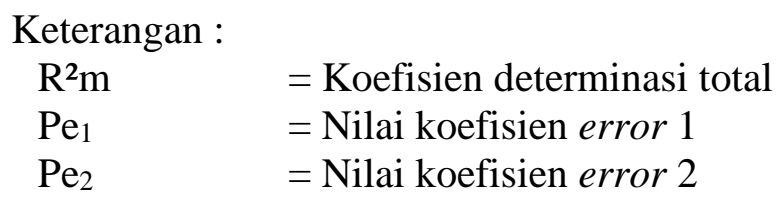

\section{HASIL DAN PEMBAHASAN}

Dalam penelitian ini teknik analisis yang digunakan adalah teknik analisis jalur (path analysis). Analisis jalur digunakan untuk menentukan pola hubungan antara tiga atau lebih dan tidak dapat digunakan untuk mengkonfirmasi atau menolak hipotesis.

Tabel 3.

Hasil Analisis Jalur Persamaan Regresi 1

\begin{tabular}{llcccccc}
\hline \multirow{2}{*}{ Model } & & \multicolumn{2}{c}{$\begin{array}{c}\text { Unstandardized } \\
\text { Coefficients }\end{array}$} & $\begin{array}{c}\text { Standardized } \\
\text { Coefficients }\end{array}$ & \multirow{2}{*}{ t } & \multirow{2}{*}{ Sig. } \\
\cline { 3 - 6 } & & B & Std. Error & Beta & & \\
\hline 1 & (Constant) & 0,061 & 0,585 & & 0,104 & 0,918 \\
& Kualitas Pelayanan & 0,235 & 0,030 & 0,687 & 7,877 & 0,000 \\
& Persepsi Harga & 0,231 & 0,083 & 0,243 & 2,783 & 0,006 \\
\hline R12 & $: 0,821$ & & & & &
\end{tabular}

F statistik : 222,180

Sig. F : 0,000

Sumber :data primer diolah, 2018

$$
\begin{aligned}
& \mathrm{Y}_{1}=\beta_{1} \mathrm{X}_{1}+\beta_{2} \mathrm{X}_{2}+\mathrm{e}_{1} \\
& \mathrm{Y}_{1}=0,687 \mathrm{X}_{1}+0,243 \mathrm{X}_{2}+\mathrm{e}_{1}
\end{aligned}
$$

Keterangan :

$$
\begin{aligned}
& \mathrm{Y}_{1}=\text { Kepuasan pelanggan } \\
& \mathrm{Y}_{2}=\text { Word of mouth } \\
& \mathrm{X}_{1}=\text { Kualitas pelayanan } \\
& \mathrm{X}_{2}=\text { Persepsi harga } \\
& \beta=\text { Koefisien garis regresi } \\
& \mathrm{e}_{1}=\text { error } 1 \\
& \mathrm{e}_{2}=\text { error } 2
\end{aligned}
$$


Ni Kadek Tjintiadewi, Pengaruh Kualitas Pelayanan Dan Persepsi...

Nilai $\beta_{1}$ adalah sebesar 0,687 memiliki arti kualitas pelayanan berpengaruh positif terhadap kepuasan pelanggan, dengan kata lain jika faktor kualitas pelayanan meningkat maka kepuasan pelanggan meningkat sebesar 0,687.

Nilai $\beta_{2}$ adalah sebesar 0,243 memiliki arti persepsi harga berpengaruh positif terhadap kepuasan pelanggan, dengan kata lain jika faktor persepsi harga meningkat maka kepuasan pelanggan meningkat sebesar 0,243.

Tabel 4.

Hasil Analisis Jalur Persamaan Regresi 2

\begin{tabular}{|c|c|c|c|c|c|c|}
\hline \multirow[t]{2}{*}{ Model } & & \multicolumn{2}{|c|}{$\begin{array}{c}\text { Unstandardized } \\
\text { Coefficients }\end{array}$} & \multirow{2}{*}{$\begin{array}{c}\begin{array}{c}\text { Standardized } \\
\text { Coefficients }\end{array} \\
\text { Beta } \\
\end{array}$} & \multirow[t]{2}{*}{$\mathbf{t}$} & \multirow[t]{2}{*}{ Sig. } \\
\hline & & B & Std. Error & & & \\
\hline \multirow[t]{4}{*}{1} & (Constant) & $-1,106$ & 0,687 & & $-1,611$ & 0,110 \\
\hline & Kualitas Pelayanan & 0,109 & 0,045 & 0,286 & 2,438 & 0,017 \\
\hline & Persepsi Harga & 0,290 & 0,101 & 0,273 & 2,863 & 0,005 \\
\hline & Kepuasan Pelanggan & 0,424 & 0,119 & 0,379 & 3,558 & 0,001 \\
\hline $\mathrm{R} 2^{2}$ & $: 0,804$ & & & & & \\
\hline F statistik & $: 131,580$ & & & & & \\
\hline Sig. F & $: 0,000$ & & & & & \\
\hline
\end{tabular}

Sumber :data primer diolah, 2018

$$
\begin{aligned}
& \mathrm{Y}_{2}=\beta_{3} \mathrm{X}_{1}+\beta_{4} \mathrm{X}_{2}+\beta_{5} \mathrm{Y}_{1}+\mathrm{e}_{2} \\
& \mathrm{Y}_{2}=0,286 \mathrm{X}_{1}+0,273 \mathrm{X}_{2}+0,379 \mathrm{Y}_{1}+\mathrm{e}_{2}
\end{aligned}
$$

Keterangan :

$\mathrm{Y}_{1}=$ Kepuasan pelanggan

$\mathrm{Y}_{2}=$ Word of mouth

$\mathrm{X}_{1}=$ Kualitas pelayanan

$\mathrm{X}_{2}=$ Persepsi harga

$\beta=$ Koefisien garis regresi

$\mathrm{e}_{1}=$ error 1

$\mathrm{e}_{2}=$ error 2

Nilai $\beta_{3}$ adalah sebesar 0,286 memiliki arti kualitas pelayanan berpengaruh positif terhadap word of mouth, dengan kata lain jika faktor kualitas pelayanan meningkat maka word of mouth meningkat sebesar 0,286 .Nilai $\beta_{4}$ adalah sebesar 0,273 memiliki arti persepsi harga berpengaruh positif terhadap word of mouth, dengan kata lain jika faktor persepsi harga meningkat maka word 
of mouth meningkat sebesar 0,273 . Nilai $\beta_{5}$ adalah sebesar 0,379 memiliki arti kepuasan pelanggan berpengaruh positif terhadap word of mouth, dengan kata lain jika faktor kepuasan pelanggan meningkat maka word of mouth meningkat sebesar 0,379 .

Berdasarkan persamaan regresi 1 dan 2 , diketahui nilai dari $\mathrm{R}_{1}{ }^{2}=0,821$ dan $\mathrm{R}_{2}^{2}=0,804$ maka nilai error untuk masing-masing persamaan dihitung sebagai berikut :

$$
\begin{aligned}
& \mathrm{e}=\sqrt{1-R^{2}} \\
& \mathrm{e}_{1}=\sqrt{1-R 1^{2}}=\sqrt{1-0,821}=0,423 \\
& \mathrm{e}_{2}=\sqrt{1-R 2^{2}}=\sqrt{1-0,804}=0,443
\end{aligned}
$$

Berdasarkan perhitungan di atas, diketahui besarnya pengaruh $\mathrm{e}_{1}=0,423$ dan nilai dari $\mathrm{e}_{2}=0,443$. Dari nilai $\mathrm{e}_{1}$ dan $\mathrm{e}_{2}$ yang telah diketahui maka koefisien determinasi total dapat dihitung sebagai berikut :

$$
\begin{aligned}
\mathrm{R}^{2} \mathrm{~m} & =1-\left(\mathrm{Pe}_{1}\right)^{2}\left(\mathrm{Pe}_{2}\right)^{2} \\
& =1-(0,423)^{2}(0,443)^{2} \\
& =1-(0,178)(0,196) \\
& =1-0,035 \\
& =0,965
\end{aligned}
$$

Koefisien determinasi total sebesar 0,965 artinya sebesar 96,5\% variasi variabel word of mouth dijelaskan oleh variabel kepuasan pelanggan, kualitas pelayanan dan persepsi harga, sedangkan sisanya sebesar 3,5\% dijelaskan oleh faktor lain yang tidak dimasukkan ke dalam model. 
Ni Kadek Tjintiadewi, Pengaruh Kualitas Pelayanan Dan Persepsi...

Hasil pada Tabel 3 dan Tabel 4 menunjukkan nilai sig. $F$ adalah 0,000. Nilai koefisien ini lebih kecil dari 0,05 sehingga dapat disimpulkan bahwa model persamaan struktural 1 dan 2 telah memenuhi syarat Goodness of Fit melalui uji F.

Hasil pada Tabel 3 diketahui pengaruh kualitas pelayanan terhadap kepuasan pelanggan memiliki koefisien $\beta_{1}=0,687$ dan pvalue sebesar 0,000. Nilai koefisien $\beta_{1}>0$ dan pvalue $\leq 0,05$ sehingga $\mathrm{H}_{1}$ diterima dan $\mathrm{H}_{0}$ ditolak. Itu berarti kualitas pelayanan berpengaruh positif dan signifikan terhadap kepuasan pelanggan.

Hasil pada Tabel 3 diketahui pengaruh persepsi harga terhadap kepuasan pelanggan memiliki koefisien $\beta_{2}=0,243$ dan $p$ value sebesar 0,006 . Nilai koefisien $\beta_{2}>0$ dan $p$ value $\leq 0,05$ sehingga $\mathrm{H}_{2}$ diterima dan $\mathrm{H}_{0}$ ditolak. Itu berarti persepsi harga berpengaruh positif dan signifikan terhadap kepuasan pelanggan.

Hasil pada Tabel 4 diketahui pengaruh kualitas pelayanan terhadap word of mouth memiliki koefisien $\beta_{3}=0,286$ dan $p$ value sebesar 0,017 . Nilai koefisien $\beta_{3}$ $>0$ dan $p$ value $\leq 0,05$ sehingga $\mathrm{H}_{3}$ diterima dan $\mathrm{H}_{0}$ ditolak. Itu berarti kualitas pelayanan berpengaruh positif dan signifikan terhadap word of mouth.

Hasil pada Tabel 4 diketahui pengaruh persepsi harga terhadap word of mouth memiliki koefisien $\beta_{4}=0,273$ dan $p$ value sebesar 0,005 . Nilai koefisien $\beta_{4}$ $>0$ dan $p$ value $\leq 0,05$ sehingga $\mathrm{H}_{4}$ diterima dan $\mathrm{H}_{0}$ ditolak. Itu berarti persepsi harga berpengaruh positif dan signifikan terhadap word of mouth.

Hasil pada Tabel 4 diketahui pengaruh kepuasan pelanggan terhadap word of mouth memiliki koefisien $\beta_{5}=0,379$ dan $p$ value sebesar 0,001 . Nilai koefisien 
$\beta_{5}>0$ dan $p$ value $\leq 0,05$ sehingga $\mathrm{H}_{5}$ diterima dan $\mathrm{H}_{0}$ ditolak. Itu berarti kepuasan pelanggan berpengaruh positif dan signifikan terhadap word of mouth.

Pengaruh antara kualitas pelayanan terhadap kepuasan pelanggan dalam penelitian ini diperoleh nilai koefisien $\beta_{1}$ sebesar 0,687 dengan tingkat signifikansi $0,000 \leq 0,05$ sehingga $\mathrm{H}_{1}$ diterima dan $\mathrm{H}_{0}$ ditolak, yang mengindikasikan bahwa kualitas pelayanan berpengaruh positif dan signifikan terhadap kepuasan pelanggan. Itu berarti, semakin baik kualitas pelayanan yang diberikan oleh RSU Prima Medika kepada para pasien maka akan semakin meningkat kepuasan yang dirasakan oleh pelanggan jasa RSU Prima Medika. Hasil rangkuman penilaian responden yang disajikan dalam deskripsi variabel penelitian menunjukkan bahwa penilaian responden terhadap kualitas pelayanan yang diberikan RSU Prima Medika Denpasar berada dalam kategori baik. Responden merasa puas dengan fasilitas fisik rumah sakit dan kesigapan karyawan dalam menangani kebutuhan dan keluhan dari pasien.Hasil penelitian ini sejalan dengan penelitian sebelumnya yang dilakukan oleh Utama (2003), Setyawati (2009), Ganguli dan Sanjit (2011), Adi (2013), Satmoko (2016), Chen et al., (2016), dan Firdous dan Rahela (2017) yang menunjukkan bahwa kualitas pelayanan berpengaruh positif dan signifikan terhadap kepuasan pelanggan.

Pengaruh antara persepsi harga terhadap kepuasan pelanggan dalam penelitian ini diperoleh nilai koefisien $\beta_{2}$ sebesar 0,243 dengan tingkat signifikansi $0,006 \leq 0,05$ sehingga $\mathrm{H}_{2}$ diterima dan $\mathrm{H}_{0}$ ditolak, yang mengindikasikan bahwa persepsi harga berpengaruh positif dan signifikan terhadap kepuasan pelanggan. Itu berarti, semakin baik persepsi harga yang 
Ni Kadek Tjintiadewi, Pengaruh Kualitas Pelayanan Dan Persepsi...

ditawarkan oleh RSU Prima Medika kepada para pasien yang ditujukan dengan harga yang relatif bersaing dengan pesaing lain maka akan semakin meningkat kepuasan yang dirasakan oleh pelanggan jasa RSU Prima Medika. Hasil rangkuman penilaian responden yang disajikan dalam deskripsi variabel penelitian menunjukkan bahwa penilaian responden terhadap harga yang ditawarkan oleh RSU Prima Medika Denpasar berada dalam kategori baik. Responden merasa puas dengan layanan kesehatan yang diterima karena sesuai dengan jumlah uang yang dibayarkan dan harga yang ditawarkan merupakan harga yang wajar. Hasil penelitian ini sejalan dengan penelitian sebelumnya yang dilakukan oleh Kertajaya (2002), Lily dan Yurike (2015), Devi dan Harry (2016) yang menunjukkan bahwa persepsi harga berpengaruh positif dan signifikan terhadap kepuasan pelanggan.

Pengaruh antara kualitas pelayanan terhadap word of mouth dalam penelitian ini diperoleh nilai koefisien $\beta_{3}$ sebesar 0,286 dengan tingkat signifikansi $0,017 \leq 0,05$ sehingga $\mathrm{H}_{3}$ diterima dan $\mathrm{H}_{0}$ ditolak, yang mengindikasikan bahwa kualitas pelayanan berpengaruh positif dan signifikan terhadap word of mouth. Itu berarti, semakin baik kualitas pelayanan yang diberikan oleh RSU Prima Medika kepada para pasien makaakan semakin mendorong terciptanya word of mouth positif tentang RSU Prima Medika. Hasil rangkuman penilaian responden yang disajikan dalam deskripsi variabel penelitian menunjukkan bahwa penilaian responden terhadap kualitas pelayanan yang diberikan oleh RSU Prima Medika Denpasar berada dalam kategori baik. Pelayanan kesehatan yang diterima pelanggan (pasien) sesuai dengan apa yang 
diharapkan yang pada akhirnya dapat meningkatkan intensitas word of mouth positif mengenai RSU Prima Medika. Hasil penelitian ini sejalan dengan penelitian sebelumnya yang dilakukan oleh Reingen dan Walker (2001), Indriani dan Nurcaya (2015), Rifky dan Yessy (2015) dan Liu dan Lee (2016) yang menunjukkan bahwa kualitas pelayanan berpengaruh positif dan signifikan terhadap word of mouth.

Pengaruh antara persepsi harga terhadap word of mouth dalam penelitian ini diperoleh nilai koefisien $\beta_{4}$ sebesar 0,273 dengan tingkat signifikansi 0,005 $\leq 0,05$ sehingga $\mathrm{H}_{4}$ diterima dan $\mathrm{H}_{0}$ ditolak, yang mengindikasikan bahwa persepsi harga berpengaruh positif dan signifikan terhadap word of mouth. Itu berarti, semakin baik persepsi harga dibenak pelanggan yang menggunakan layanan jasa kesehatan di RSU Prima Medika maka akan semakin mendorong terciptanya word of mouth positif kepada orang-orang disekitarnya. Hasil rangkuman penilaian responden yang disajikan dalam deskripsi variabel penelitian menunjukkan bahwa penilaian responden terhadap persepsi harga yang diberikan oleh RSU Prima Medika Denpasar berada dalam kategori baik. Responden menilai harga yang ditawarkan oleh RSU Prima Medika sesuai dengan pelayanan yang diberikan. Selain itu kesesuaian harga dibandingkan dengan rumah sakit pesaing menjadikan intensitas word of mouth positif mengenai RSU Prima Medikameningkat. Hasil penelitian ini sejalan dengan penelitian sebelumnya yang dilakukan oleh Nurjanah dan Mashariono (2017), Anik (2013) dan Neni (2017) yang menunjukkan bahwa persepsi harga berpengaruh positif dan signifikan terhadap word of mouth. 
Ni Kadek Tjintiadewi, Pengaruh Kualitas Pelayanan Dan Persepsi...

Pengaruh antara kepuasan pelanggan terhadap word of mouth dalam penelitian ini diperoleh nilai koefisien $\beta_{5}$ sebesar 0,378 dengan tingkat signifikansi $0,001 \leq 0,05$ sehingga $\mathrm{H}_{5}$ diterima dan $\mathrm{H}_{0}$ ditolak, yang mengindikasikan bahwa kepuasan pelanggan berpengaruh positif dan signifikan terhadap word of mouth. Itu berarti, semakin tinggi kepuasan yang dirasakan oleh pelanggan setelah menggunakan layanan jasa kesehatan di RSU Prima Medika maka akan semakin mendorong meningkatnya intensitas word of mouth positif kepada orang-orang disekitarnya. Hasil rangkuman penilaian responden yang disajikan dalam deskripsi variabel penelitian menunjukkan bahwa penilaian responden terhadap kepuasan pelanggan yang menggunakan pelayanan jasa kesehatan di RSU Prima Medika Denpasar berada dalam kategori baik. Responden merasa kepuasannya terpenuhi setelah menggunakan layanan kesehatan yang berkualitas dan harga yang dianggap sebanding dengan apa yang didapatkan sehingga intensitas word of mouth positif mengenai RSU Prima Medika meningkat. Hasil penelitian ini sejalan dengan penelitian sebelumnya yang dilakukan oleh Priharmoko (2003), Erida (2009), Yuli dan Bagus (2014) dan Primantara (2017) yang menunjukkan bahwa kepuasan pelanggan berpengaruh positif dan signifikan terhadap word of mouth.

Implikasi hasil penelitian ini menekankan pada manfaat dari hasil penelitian yang dapat dijadikan strategi di dalam memasarkan produk jasa dengan menyajikan pelayanan yang optimal dan kesesuaian harga sehingga membuat pelanggan puas dan menciptakan word of mouth yang positif. Kualitas pelayanan merupakan komponen yang mampu meningkatkan kepuasan pelanggan jasa 
kesehatan RSU Prima Medika. Penting bagi perusahaan untuk tetap fokus menjaga dan meningkatkan kualitas melalui penyediaan peralatan medis yang modern, melatih kesigapan dan profesionalisme karyawan dalam menanggapi permintaan atau keluhan pasien, memberikan pelayanan sesuai dengan janji,selalu memberi rasa aman dan nyaman kepada setiap pelanggan (pasien) serta selalu mengutamakan kepentingan mereka. Hal ini dapat menjadi strategi perusahaan untuk dapat meningkatkan kepuasan pelanggan dan pada akhirnya akan mendorong timbulnya word of mouth yang positif mengenai RSU Prima Medika.

Persepsi harga merupakan komponen yang mampu meningkatkan kepuasan pelanggan RSU Prima Medika. Dengan menawarkan harga terbaik yang relatif mampu bersaing dengan rumah sakit lainnya, dan layanan kesehatan yang berkualitas yang sesuai dengan jumlah uang yang dibayarkan diharapkan hal ini dapat menjadi strategi perusahaan untuk meningkatkan kepuasan pelanggan yang pada akhirnya bermuara pada intensitas word of mouth positif yang terus meningkat mengenai RSU Prima Medika.

Kepuasan pelanggan terhadap pelayanan yang diterima merupakan salah satu faktor yang mampu meningkatkan intensitas word of mouth positif. Pelanggan yang merasa puas secara keseluruhan terhadap pelayanan yang diberikan dapat menjadi strategi perusahaan untuk meningkatkan word of mouth positif, karena pelanggan yang puas akan merekomendasikan pelayanan jasa kesehatan RSU Prima Medika kepada orang lain disekitarnya. 
Ni Kadek Tjintiadewi, Pengaruh Kualitas Pelayanan Dan Persepsi...

\section{SIMPULAN DAN SARAN}

Berdasarkan hasil penelitian maka dapat ditarik kesimpulan bahwa kualitas pelayanan berpengaruh positif dan signifikan terhadap kepuasan pelanggan. Persepsi harga berpengaruh positif dan signifikan terhadapkepuasan pelanggan. Kualitas pelayananberpengaruh positif dan signifikan terhadap word of mouth. Persepsi harga berpengaruh positif dan signifikan terhadap word of mouth. Kepuasan pelanggan berpengaruh positif dan signifikan terhadap word of mouth.

Saran yang dapat diberikan berdasarkan kesimpulan yang dipaparkan kepada perusahaan dan penelitian selanjutnya adalah perusahaan diharapkan agar fokus untuk memberikan perhatian khusus pada pasien rawat jalan maupun pasien rawat inap. Perusahaan diharapkan agar lebih mempertimbangkan harga yang ditawarkan kepada pasien guna memenangkan persaingan dengan rumah sakit lainnya. Perusahaan diharapkan agar lebih meningkatkan kualitas layanan rumah sakit dengan memenuhi seluruh kebutuhan pasien agar pasien merasa puas setelah menggunakan layanan jasa di RSU Prima Medika. Perusahaan diharapkan lebih meningkatkan performa layanan guna tercapainya rasa puas yang dirasakan pasien yang selanjutkan akan merekomendasikan pengalamannya selama menggunakan pelayanan kesehatan di RSU Prima Medika.

\section{REFERENSI}

Erida. 2009. Pengaruh Kepuasan Konsumen dan Insentif Terhadap Perilaku WOM (Word Of Mouth) Konsumen Jasa Angkutan Penumpang Bis Antar Kota Antar Propinsi Kelas Eksekutif Di Bandung.Jurnal Manajemen Pemasaran ModernUniversitas Jambi,1 (1), 1-60.

Ferdinand, Augusty. 2002. Structural Equation Modelling Dalam Penelitian Manajemen Aplikasi Model-Model Rumit Dalam Penelitian untuk Tesis Magister dan Disertasi Doktor. Semarang : BP UNDIP 
Firdous, Sadaf and Rahela Farooqi. 2017. Impact of Internet Banking Service Quality on Customer Satisfaction. Journal Internet Bank Commerce, 22 (1), $1-17$.

Ganguli, Shirshendu dan Sanjit Kumar. 2011. Generic Technology Based Service Quality Dimensions in Banking: Impact on Customer Satisfaction and Loyalty. International Journal of Bank Marketing, 29 (2), 168-189.

Harjati, Lily dan Yurike Venesia. 2015. Pengaruh Kualitas Layanan dan Persepsi Harga Terhadap Kepuasan Pelanggan Pada Maskapai Penerbangan Tiger Air Mandala. E-Journal Widya Ekonomika, 1 (1), 164-174.

Harrison-Walker, L. Jean. 2001. The Measurement of Word of Mouth Communication and an Investigation of Service Quality and Customer Commitment as Potential Antecedents. Journal of Service Research, 4 (1), 60-75.

Indriani, Sagung dan Nurcaya. 2015. Pengaruh Kualitas Pelayanan Terhadap Word Of Mouth yang Dimediasi Oleh Kepercayaan Pelanggan Pada PT. Auto Bagus Rent A Car Denpasar. E-Jurnal Manajemen Unud, 4 (5),13011321.

Kertajaya, Hermawan. 2002. Hermawan Kertajaya on Marketing. Edisi Soft Cover. Bandung: Mizan Media Utama.

Kotler, Philip \& Kevin L. Keller. 2009. Manajemen Pemasaran jilid 1, edisi Ketiga belas, Terjemahan Bob Sabran. Jakarta: Erlangga. Hal:143.

Kotler, Philip. 2000. Manajemen Pemasaran. Edisi ke 10. Jakarta : PT. Ikrar Mandiri Abadi.

Lestari, Anik. 2013. Pengaruh Kualitas Layanan dan Harga Terhadap Word Of MouthDengan Kepuasan Pelanggan Sebagai Variabel Intervening (Studi Pada Pengunjung Timezone Plaza Surabaya). Journal Buletin Ekonomi. 11 (11), 1-86.

Liu, Chih Hsing Sam dan Tingko Lee. 2016. Service Quality and Price Perception Of Service: Influence on Word Of Mouth and Revisit Intention. Journal of Air Transport Management, 52,42-54.

Lovelock, Cristhoper dan Jochen Wirtz. 2011. Service Marketing. New Jersey USA: Pearson. Hal:74.

Molinari, Lori K., Russell Abratt., dan Paul Dion. 2008. Satisfaction, Quality and Value and Effects on Repurchase and Positive Word of Mouth Behavioral Intention in a B2B Services Context. Journal of Service Marketing,22 (5), 363-373.

Nurjanah, Rukhianan dan Mashariono. 2017. Pengaruh Produk dan Harga Terhadap Word Of Mouth Melalui Kepuasan Konsumen. Jurnal Ilmu dan Riset Manajemen, 6 (7), 1-17. 
Novianti, Rifky dan Yessy Artanti. 2015. Pengaruh Kualitas Layanan Terhadap Word Of Mouth (WOM) Melalui Kepuasan Sebagai Variabel Intervening. Jurnal Ilmu Manajemen, 1 (1), 1-11.

Priharmoko, P. 2003. Faktor-Faktor Yang Mempengaruhi Perilaku WordOfMouth Pada Konsumen. Studi kasus : Pelanggan Kartu Halo di DKI Jakarta, Tesis tidak diterbitkan, Program Pasca sarjana Ilmu Komunikasi. Universitas Indonesia, Depok.

Primantara, Windu. 2017. Peran Kepuasan Memediasi Kualitas Layanan Terhadap WOM Pada RSU Surya Husadha Denpasar. E-Jurnal Manajemen pada Fakultas Ekonomi dan Bisnis Universitas Udayana, 6 (7), 3794-3819.

Rahmawati, Yuli dan Bagus Suminar. 2014. Pengaruh Kepuasan dan Loyalitas Pelanggan Terhadap Word Of Mouth Pada Pelanggan Honda Motor di Surabaya. Journal of Business and Banking, 4 (7), 15-30.

Rambe, Neni dan Choiril Maksum. 2017. Pengaruh Pelayanan, Citra Merek dan Harga Terhadap Pembelian Ulang Melalui Kepuasan Pelanggandan Word Of Mouth. Sekolah Pascasarjana Universitas Pancasila.

Reingen, P. H., and Walker, B. A. 2001. Cross-Unit Competition for a Market Charter: The Enduring Influence of Structure, Journal of Marketing, 65, 2931.

Resti, Devi dan Harry Soesanto. 2016. Pengaruh Persepsi Harga, Kualitas Pelayanan Melalui Kepuasan Pelanggan Terhadap Minat Beli Ulang Pada Rumah Kecantikan Sifra di Pati. Diponegoro Journal Of Management, 5 (1), 1-12.

Riduwan dan Kuncoro, Engkos Achmad. 2008. Cara Menggunakan dan Memaknai Analisis Jalur (Path Analysis). Bandung : Alfabeta.

Saraswulandari, Irma dan I Wayan Santika. 2013. Keterlibatan Produk Dan Keterlibatan Situasional dalam Memoderasi Pengaruh Kepuasan Konsumen Terhadap Word of Mouth. E-Jurnal Manajemen pada Fakultas Ekonomi dan Bisnis Universitas Udayana, 3 (6), 1552-1570.

Satmoko, Taufiq Dwi. 2016. Pengaruh Kualitas Pelayanan TerhadapWord Of Mouth, Melalui Kepercayaan dan Kepuasan Konsumen Sebagai Variabel Intervening Pada Star Clean Car Wash Semarang. E Journal UNDIP, 5 (1), $1-10$.

Setyawati, Indah. 2009. Analisis Pengaruh Kualitas Layanan Dan Kepuasan Pasien Terhadap Word Of Mouth (Studi pada Pasien Rawat Jalan RS. Bhakti Wira Tamtama Semarang). Tesis, Program Studi Magister Manajemen Universitas Diponogoro, Semarang.

Shao-Chang Li. 2013. Exploring The Relationships among Service Quality, Customer Loyalty and Word of Mouth for Private Higher Education in Taiwan. Asia Pasific Management Review, 18 (4), 375-389.

Sugiyono, 2017. Metode Penelitian Bisnis. Bandung : Penerbit Alfabeta 
Sulistyowati, Liliek Nur. 2008. Pengaruh Persepsi Atas Produk dan Pelayanan Terhadap Kepuasan Pelanggan dan Perilaku Word Of MouthPada LBB "X" Maospati, Magetan. Media Soerjo, 3 (2),17-33.

Supartiningsih, Solichah. 2017. Kualitas Pelayanan dan Kepuasan Pasien Rumah Sakit:Kasus Pada Pasien Rawat Jalan. Jurnal Medicoeticolegal dan Manajemen Rumah Sakit, 6 (1),9-15.

Trarintya, Putri. 2011. Pengaruh Kualitas Pelayanan Terhadap Kepuasan dan Word Of Mouth (Studi Kasus Pasien Rawat Jalan di Wing Amertha RSUP Sanglah Denpasar). Pps.unud/thesis.

Utama, Agung. 2003. Analisis Pengaruh Persepsi Kualitas Pelayanan terhadap Kepuasan Pelanggan Rumah Sakit Umum Cakra Husada Klaten. Staf Pengajar Fakultas Ekonomi UPN Veteran Yogyakarta, 1 (2), 96-110.

www.primamedika.com.Diakses pada 22 Oktober 2017.

Xiaohong Chen, Lujun Su, dan Scott R. Swanson. 2016. The Effects Of Perceived Service Quality On Repurchase Intentions and Subjective Well-Being Of Chinese Tourists: The Mediating Role Of Relationship Quality. Tourism Management, 52,82-95. 